\title{
Evaluasi Penilaian Pelaksanaan Standard Manajemen Informasi dan Rekam Medis (MIRM) di Rumah Sakit
}

\section{Evaluation of the Assessment of "Manajemen Informasi dan Rekam Medis (MIRM)" Standart in Hospitals}

\author{
Elise Garmelia ${ }^{1}$ \\ Siswati ${ }^{2}$ \\ Sri Sugiarsi ${ }^{3}$
}

1) Poltekkes Kemenkes Semarang

Jalan Tirto Agung, Pedalangan, Banyumanik, Semarang, Jawa Tengah

2) Rumah Sakit Husada

Jl. Raya Mangga Besar No.137, RW.1, Mangga Dua Selatan, Sawah Besar,Jakarta Pusat

3) Stikes Mitra Husada Karanganyar

Jl. Brigjen Katamso Barat, Gapura Papahan Indah, Papahan, Kec. Tasikmadu, Kabupaten Karanganyar, Jawa Tengah

Email : elsa0360@gmail.com

\begin{abstract}
According to the Ministry of Health, Republic of Indonesia, accreditation is a step to ensure hospitals to prioritize the service, safety and protection of the community. Hospitals as one of the health care institutions are required to provide quality services including in the implementation of medical records and health information that are in the standard of "Manajemen Informasi Rekam Medis" (MIRM). The purpose of the research is to know the value of accreditation in MIRM standard instruments 8-15 namely medical record management from hospitals in 3 (three) regions in Indonesia. This research is quantitative descriptive research with a sample count of 14 hospitals. Data processing through scoring elements in SNARS 1.1 edition and processing with SPSS to analyze the value of relationship scoring elements of assessment in government and non-government hospitals. Analysis with Anova, independent simple test and multiple comparison. The result is that there is a significant difference of $p=0.00(p<0.05)$ of scores or assessment elements between the 3 hospital areas, but there is no significant difference (o.788) $\mathrm{p}>0.05$ ) standard value (8-15) between government and non-government hospitals. The conclusion is the assessment standard of KARS that the fulfillment of MIRM (8-15) standards of both facilities, infrastructure and human resources has not been evenly distributed in every hospital in the 3 regions, while the use of every element of the assessment of MIRM standard ( 8-15) is standard for government hospitals of various classes as well as for non-government hospitals.
\end{abstract}

Keywords : Accreditation; MIRM standard

\begin{abstract}
Abstrak
Menurut Kementerian kesehatan bahwa akreditasi adalah langkah untuk menjamin rumah sakit agar mengutamakan pelayanan, keselamatan dan perlindungan masyarakat. Rumah sakit sebagai salah satu institusi pelayanan kesehatan dituntut untuk memberikan pelayanan yang bermutu termasuk dalam penyelenggaraan rekam medis dan informasi kesehatan yang tersebut pada standard Manajemen Informasi dan Rekam Medis ( MIRM). Tujuan penelitian adalah ingin mengetahui nilai akreditasi pada instrumen MIRM standar 8-15
\end{abstract}


yakni manajemen rekam medis dari rumah sakit di 3 (tiga) wilayah di Indonesia. Penelitian ini merupakan penelitian deskriptif kuantitatif dengan jumlah sampel 14 rumah sakit. Pengolahan data melalui Skor setiap elemen penilaian yang ada pada buku SNARS edisi 1.1 dan pengolahan dengan SPSS untuk menganalisis hubungan nilai skor elemen penilaian di rumah sakit pemerintah dan non pemerintah. Analisis dengan Anova, uji independent simple test dan multiple comparison. Dengan hasil ada perbedaan signifikan $\mathrm{p}=0,00(\mathrm{p}<0.05)$ skor atau elemen penilaian diantara 3 wilayah rumah sakit, namun tidak ada perbedaan $(0,788) p>0,05)$ yang signifikan nilai standard (8-15) antara RS pemerintah dan non pemerintah. Kesimpulan adalah adanya standar penilaian dari KARS bahwa pemenuhan standar MIRM (8-15) baik sarana, prasarana dan SDM belum merata di setiap rumah sakit di 3 wilayah tersebut, sedangkan penggunaan setiap elemen penilaian dari standard MIRM ( 8-15) adalah baku bagi rumah sakit pemerintah berbagai kelas maupun untuk rumah sakit non pemerintah.

Kata kunci : Akreditas; standar MIRM

\section{Pendahuluan}

Sebagaimana yang disebutkan dalam Undang - Undang No 44 Tahun 2009 mengenai akreditasi disebutkan bahwa akreditasi harus dilakukan secara berkala oleh sebuah rumah sakit setiap minimal 3 (tiga) tahun sekali dalam upaya penungkatan mutu pelayanan (pasal 40, UU No.44 Tahun 2009).Informasi Rumah sakit terkait asuhan pasien sangat penting untuk komunikasi antar staf klinis, yang didokumentasikan dalam Rekam Medis Rekam medis (RM) adalah bukti tertulis (kertas/eletronik) yang merekam berbagai informasikes ehatan pasien seperti temuan hasil asesmen, rencana asuhan, rincian pelaksanaan asuhan dan pengobatan, catatan perkembangan pasien terintegrasi, serta ringkasan kepulangan pasien yang dibuat oleh Profesional Pemberi Asuhan (PPA).

Menurut Permenkes 12 tahun 202-, akreditasi adalah pengakuan yang diberikan kepada rumah sakit karena telah berupaya meningkatkan mutu pelayanan secara berkesinambungan.

Pengakuan ini diberikan oleh lembaga independen yang bertugas melakukan akreditasi dan sudah memperoleh pengakuan dari Menteri Kesehatan. Lembaga independen yang bertugas melakukan akreditasi terhadap rumah sakit di Indonesia adalah Komisi Akreditasi Rumah sakit (KARS).

Menurut Lumenta (2003) akreditasi sangat berkaitan erat dengan mutu pelayanan yang diberikan rumah sakit. Artinya jika akreditasi dilakukan dengan baik, maka akan terjadi peningkatan mutu pelayanan rumah sakit. Namun menurut Pangestuti, Kuntjoro dan Utarini (2002) hasil akreditasi tidak otomatis meningkatkan kualitas pelayanan rumah sakit.

Menurut Peraturan Menteri Kesehatan Republik Indonesia Nomor 269 Tahun 2008 rekam medis merupakan berkas yang berisikan catatan dan dokumen tentang identitas pasien, pemeriksaan, pengobatan, tindakan dan pelayanan lain yang telah diberikan kepada pasien. Penyelenggaraan rekam medis merupakan proses kegiatan yang dimulai saat pasien diterima di rumah sakit sampai dengan pencatatan data medis, keperawatan, manajer pelayanan pasien (MPP) serta PPA lainya selama pasien mendapat asuhan.

Tujuan penelitian ini adalah mengetahui gambaran pelaksanaan nilai akreditasi pada instrumen MIRM standar 815 di wilayah Jawa, sumatera, dan Sulawesi.

\section{Metode}

Penelitian ini dilakukan dengan 
pendekatan kuantitatif, data penilaian akreditasi dari 14 rumah sakit di wilayah Sumatera, Jawa dan Sulawesi. Dari 14 rumah sakit yang di akreditasi terdiri dari 2 RS kelas A, RS Kelas B ada 5 RS dan 7 RS dari kelas C. Penilaian menggunakan instrumen untuk 8 standard. Manajemen Rekam Medis terdiri atas 13 Standar dengan 52 elemen penilaian. Penilaian dari masingmasing elemen penilaian adalah sebagai berikut : Skor 10 (terpenuhi lengkap), yaitu bila rumah sakit dapat memenuhi elemen penilaian tersebut minimal $80 \%$, Skor 5 (terpenuhi sebagian) yaitu bila rumah sakit dapat memenuhi elemen penilaian tersebut antara $20-79 \%$, Skor 0 (tidak terpenuhi) yaitu bila rumah sakit hanya dapat memenuhi elemen penilaian tersebut kurang dari $20 \%$.

\section{Hasil dan Pembahasan}

Semakin berkembangnya asuransi kesehatan pelayanan rumah sakit yang sesuai standar semakin dibutuhkan sehingga pelaksanaan akreditasi menjadi penting, dengan dilaksanakannya akreditasi rumah sakit maka pembinaan standar yang ditetapkan agar mutu pelayanan dapat dipergunakan untuk mengukur kinerja rumah sakit. Oleh karna adanya tuntutan akan mutu pelayanan yang harus lebih meningkat, maka dilakukan penelitian tentang Evaluasi penilaian pelaksanaan standard manajemen informasi dan rekam medis (MIRM) di rumah sakit.

Tujuan pengelolaan rekam medis dan informasi kesehatan adalah menunjang tertib administrasi dalam rangka upaya peningkatan pelayanan kesehatan di rumah sakit yang didukung oleh suatu sistem pengelolaan rekam medis yang cepat, tepat, bernilai, dapat dipertanggungjawabkan serta berfokus kepada pasien dan keselamatan pasien secara terintegrasi.

Standar Manajemen Informasi dan Rekam Medis (MIRM) merupakan Bab 15 dari SNARS ed. 1.1. Standar MIRM terdiri dari 2 (dua) sub bab yakni, Manajemen Informasi dari standar 1-7 dan Manajemen Rekam Medis dari standar 8 - 15. Namun penelitian ini hanya mengevaluasi standar 8- 15 saja, yakni Manajemen Rekam Medis.

Kegiatan dilanjutkan dengan penanganan rekam medis yang meliputi penyimpanan dan penggunaan untuk kepentingan pasien atau keperluan lainnya.

Rekam Medis memiliki kegunaan sebagai:

1. Alat komunikasi antara professional pemberi asuhan (PPA) yang memberikan asuhan (communication);

2. Dasar dalam perhitungan biaya pelayanan kepada pasien [financial biling).

3. Penyedia data khusus yang sangat berguna untuk keperluan penelitian dan pendidikan [research $\mathcal{E}$ education).

4. Dasar untuk merencanakan asuhan yang harus diberikan kepada pasien [assessment).

5. Bahan yang berguna untuk analisis, penelitian, dan evaluasi kualitas pelayanan yang diberikan kepada pasien (audit klinis)

6. Sumber ingatan yang harus didokumentasikan serta sebagai bahan pertanggungjawaban dan pelaporan.

7. Bukti tertulis/terekam atas segala tindakan pelayanan, perkembangan penyakit, dan pengobatan selama pasien berkunjung/dirawat di rumah sakit.

8. Pelindung kepentingan hukum bagi pasien, rumah sakitmaupun PPA [legal documentation).

Penelitian Murti Mandawati dkk pada Jurnal Keperawatan dan Pemikiran Ilmiah bahwa ada dampak positif dari pelaksanaan akreditasi bagi pelayanan dengan meningkatnya usaha keselamatan pasien, selain itu akreditasi juga memberikan dampak pada perbaikan fasilitas dan lingkungan kerja. 
Tabel 1. Distribusi RS yang dinilai berdasarkan RS Pemerintah dan non Pemerintah

\begin{tabular}{|c|c|c|c|c|c|c|}
\hline \multirow[b]{2}{*}{ No } & \multirow[b]{2}{*}{$\begin{array}{c}\text { Type / kelas } \\
\text { RS }\end{array}$} & \multicolumn{5}{|c|}{ Wilayah } \\
\hline & & 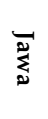 & 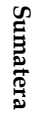 & 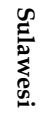 & $\begin{array}{l}\bar{\Xi} \\
\bar{\partial} \\
\vec{\partial}\end{array}$ & $\%$ \\
\hline 1 & $\begin{array}{l}\text { RS } \\
\text { Pemerintah }\end{array}$ & 3 & 4 & 1 & 7 & $50 \%$ \\
\hline 2 & $\begin{array}{l}\text { RS non } \\
\text { Pemerintah } \\
\text { Jumlah }\end{array}$ & 3 & 1 & 2 & 14 & $50 \%$ \\
\hline
\end{tabular}

Tabel 2. Distribusi RS yang dinilai berdasarkan Tipe RS

\begin{tabular}{|c|c|c|c|c|c|c|}
\hline \multirow[b]{2}{*}{ No } & \multirow[b]{2}{*}{$\begin{array}{c}\text { Tipe / kelas } \\
\text { RS }\end{array}$} & \multicolumn{5}{|c|}{ Wilayah } \\
\hline & & $\overline{\sum_{0}^{\infty}}$ & 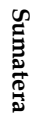 & 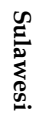 & $\begin{array}{l}\bar{E} \\
\stackrel{\Xi}{2}\end{array}$ & $\%$ \\
\hline 1 & RS Type A & 2 & & & 2 & $14,28 \%$ \\
\hline 2 & RS Type B & 2 & 3 & & 5 & $35,72 \%$ \\
\hline \multirow[t]{2}{*}{3} & RS Type C & 2 & 2 & 3 & 7 & $50 \%$ \\
\hline & Jumlah & 6 & 5 & 3 & 14 & \\
\hline
\end{tabular}

Dari 14 Rumah Sakit terdiri dari 6 RS dari wilayah Jawa, 3 RS dari wilayah Sulawesi dan 5 RS dari wilayah Sumatera.

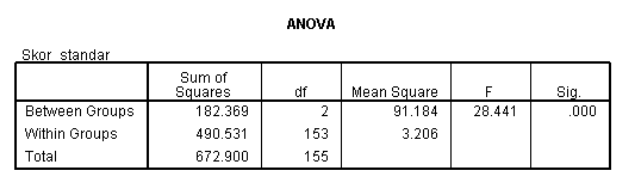

Post Hoc Tests

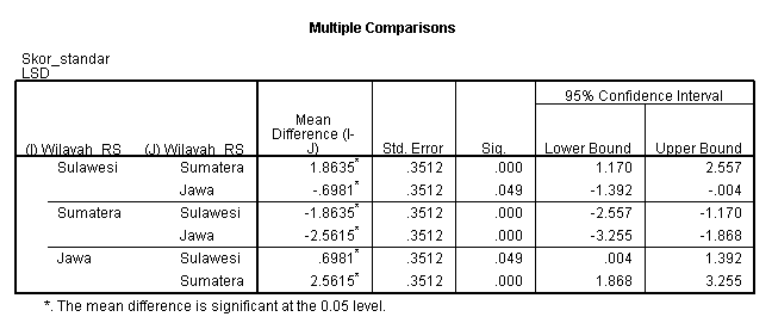

Gambar 1. Hasil Analisis Anova

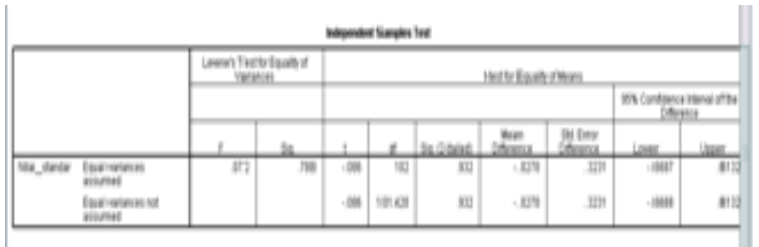

Gambar 2. Independent Simple Test

Dilakukan Analisis dengan Anova (Gambar 1) bahwa ada perbedaan yang signifikan $p=0,00(p<0.05)$ skor atau setiap element penilaian standard 8-15 diantara rumah sakit wilayah Jawa, Sumatera dan Sulawesi. Hal ini dikarenakan dalam pemenuhan setiap elemen penilaian, kemampuan masing-masing RS di wilayah tersebut tidak sama seperti sarana, prasarana dan kompetensi pengelola manajemen rekam medis (kurangnya SDM). Uji multiple comparison tersebut membuktikan bahwa penggunaan instrumen elemen penilaian pada standar MIRM 8-15 adalah sama di setiap RS yakni menggunakan instrumen SNARS ed.1.1.

Seperti pada MIRM 8, Organisasi pengelola rekam medis dipimpin tenaga rekam medis yang memiliki kompetensi dan kewenangan mengelola rekam medis sesuai dengan peraturan perundanganundangan.

Pada MIRM 1 (ARK 2) belum semua RS memiliki proses pendaftaran rawat inap berbasis SIM-RS sehingga publik dapat mengetahui tempat / fasilitas yang masih tersedia.

MIRM 9 masih kurangnya fasilitas tempat penyimpanan yang menjamin keamanan dan kerahasiaan rekam medis. MIRM 13 yakni belum dilakukan secara berkala tentang review rekam medis dan belum menggunakan sampel yang mewakili dari jumlah dan jenis sampel yang akan di review

Penggunaan setiap elemen penilaian dari standard MIRM ( 8-15) sudah baku menjadi standar penilaian Akreditasi bagi rumah sakit pemerintah berbagai kelas maupun untuk rumah sakit non pemerintah

Berdasarkan analisis independent simple test (Gambar 2), diketahui bahwa tidak ada perbedaan yang signifikan $(0,788) \mathrm{p}>0,05)$ pada nilai standar (8-15) antara RS pemerintah dan non pemerintah.

\section{Simpulan dan Saran}

Evaluasi dari penelitian ini terhadap 14 rumah sakit diketahui ada standar penilaian 
dari KARS terkait pemenuhan standar MIRM (8-15) baik sarana, prasarana dan SDM yang belum merata di setiap rumah sakit di 3 wilayah (Jawa, Sumatera dan Sulawesi), sedangkan penggunaan setiap elemen penilaian dari standar MIRM (8-15) adalah baku bagi rumah sakit pemerintah berbagai kelas maupun untuk rumah sakit non pemerintah. Perlu adanya penelitian lanjutan untuk MIRM standar 1-7 untuk melengkapi nilai total MIRM terkait kesiapan dan kelengkapan sarana dan infrastruktur terkait SIMRS dengan manajemen rekam medis.

\section{Ucapan Terima Kasih}

Terima kasih disampaikan kepada Poltekkes Kemenkes Semarang yang telah mendanai penelitian ini.

\section{Daftar Pustaka}

Dedent Eka, dkk. 2017. Evaluasi tingkat kesesuaian standar akreditasi terhadap pelayanan farmasi dan strategi perbaikan dengan metode hanlon di rsud kabupaten Bima. JIME, Vol. 3. No. 2 ISSN 2442-9511

https://galihendradita.wordpress.com/201 8/06/06/kebijakan-cara-penilaiandalam-snars-kars-2018/

(diakses tanggal 13 Oktober 2020)

Kathleen M. LaTour. 2010. Health Informaton management: Concept, Principle, and Practice 3rd ed., p. 544545. AHIMA

Komisi Akreditasi Rumah Sakit. 2018. Standard Nasional Akreditasi Rumah Sakit ed. 1.1. KARS, Jakarta: Komisi Akreditasi Rumah Sakit

Mandawati, Murti dkk. 2018. Dampak Akreditasi Rumah Sakit : Studi Kualitatif Terhadap Perawat di RSUD KRT Setjonegoro Wonosobo. Nurscope. Jurnal Keparawatan
Pemikiran Ilmiah 4(4)

Novi mesrina c, nuryati, s.far., m.p.h. 2018. Tinjauan Pemenuhan Elemen Penilaian MIRM 11 SNARS di Rumah Sakit Umum Kabanjahe. Yogyakarta: Sekolah vokasi UGM

Pamela K. Oachs and Amy L Watters. 2016. Health Informaton management: Concept, Principle, and Practice 5th p. 121-126. AHIMA

Peraturan Menteri Kesehatan No 55 Tahun 2013 tentang Penyelenggaraan rekam medis. 2013. Jakarta: Kementerian Kesehatan Republik Indonesia

Peraturan Menteri Kesehatan Republik Indonesia No 12 Tahun 2012 tentang Akreditasi Rumah Sakit. 2012. Jakarta: Kementerian Kesehatan Republik Indonesia

Peraturan Menteri Kesehatan Republik Indonesia No 12 tahun 2012 tentang Akreditasi rumah sakit. 2012. Jakarta: Kementerian Kesehatan Republik Indonesia

Peraturan Menteri Kesehatan Republik Indonesia No 129 Tahun 2008 tentang Standar Pelayanan Minimal. 2008. Jakarta: Kementerian Kesehatan Republik Indonesia

Peraturan Menteri Kesehatan Republik Indonesia No 269 tahun 2008 tentang Rekam Medis. 2008. Jakarta: Kementerian Kesehatan Republik Indonesia

Peraturan Menteri Kesehatan Republik Indonesia Nomor 3 Tahun 2020 Tentang Klasifikasi dan Perizinan Rumah Sakit. 2020. Jakarta : Kementerian Kesehatan Republik Indonesia

Peraturan Menteri Kesehatan Republik Indonesia. No 312 Tahun 2020 tentang 
Standar Profesi Perekam Medis dan Informasi Kesehatan. 2020. Jakarta : Kementerian Kesehatan Republik Indonesia

Putera, Arief Budiman, dr. Tjahjono Kuntjoro, MPH, Dr PH. 2010. Tingkat Kesesuaian Standar Akreditasi Terhadap Strategi dan Rencana Pengembangan Pelayanan Instalasi Gawat Darurat : Studi kasus di Rumah Sakit Umum Daerah Cut Meutia Aceh Utara. S2 IKMKebijakan dan Manajemen Pelayanan Kesehatan.

Undang-Undang No 44 Tahun 2009 tentang Rumah Sakit. 2009. Jakarta: Republik Indonesia 